\title{
English Name Transition from Taiwan to the United States: A Case Study of Taiwanese International Students
}

\author{
Yi-An Jason Chen (Corresponding author) \\ Department of Linguistics, University of Florida, United States \\ E-mail: smallg11@ufl.edu
}

Received: 25-01-2016

Published: 01-07-2016
Accepted: 11-04-2016

doi:10.7575/aiac.ijalel.v.5n.4p.58
Advance Access Published: May 2016

URL: http://dx.doi.org/10.7575/aiac.ijalel.v.5n.4p.58

\begin{abstract}
The way in which Taiwanese students use English names to construct their identities in a new sociocultural setting has received minimal scholarly attention. Drawing on semi-structured interviews with 10 Taiwanese international students, I focused on how the use of ethnic names and English names is structured through social interaction and cultural context at an American university. The results suggest that the acquisition of an English name is not a personal choice, but an authoritative order that originates from private English education in Taiwan. Even though the choice of ethnic and English names in the United States is often constrained by linguistic factors, the use of English names by Taiwanese international students not only discloses their attitudes toward English name adoption, but also greatly influences their identity and acculturation.
\end{abstract}

Keywords: Taiwanese International Students, English Names, Ethnic Names, Identity, English Education, Acculturation

\section{Introduction}

The pursuit of higher education in the United States by international students has drawn attention to the fact that, although a small country, Taiwan has one of the largest U.S. international student populations (Institute of International Education, 2011a). Of the 723277 foreign students enrolled in U.S. colleges and universities in the 2010-2011 academic year, Taiwanese comprised the fifth-largest national group, with 24818 students (Institute of International Education, 2011b). The United States boasts the world's largest international student population. The growing number of international students brought a massive influx of money-more than $\$ 21$ billion-into to the U.S. economy in 2010 (Institute of International Education, 2011b).

International students from diverse countries have promoted considerable linguistic and cultural diversity on American campuses. In addition, each ethnic group may exhibit specific cultural patterns that are exclusively shared by group members. It was found that Taiwanese students seemed more likely than other East Asian students-such as those from Japan, Korea and China - to use English names rather than their original ethnic names when communicating with both native and non-native English speakers at American universities (Chen, 2013). The use of English names is seemingly prevalent among Taiwanese students, but questions about the interface between their names and identities remain puzzling.

As yet only a handful of studies within the past two decades have examined the adoption and use of ethnic or English names by Asian international students and Asian immigrants residing in English-speaking host countries (Burke, 2001; Edwards, 2006; Heffernan, 2010; Kim, 2007; Li, 1997; Thompson, 2006). These studies have shown that Asian students' choice of ethnic or English names is not only sensitive to variations in the social settings but also closely interwoven with their identities. In light of this gap, the present study will contribute to examining the use of ethnic and English names by Taiwanese international students studying in the United States. The aim of this case study is to identify how the use of ethnic and English names by Taiwanese international students is structured through social interaction and cultural context at an American university.

\section{Literature Review}

Several researchers have identified diverse Asian ethnic groups in order to compare how they respond to English name adoption. The mispronunciation of one's ethnic name can pose psychological problems that undermine Asian students' self-esteem in English-speaking environments. The mispronunciation of ethnic names by native English speakers may cause unpleasant experiences for Asian students; thus students from Taiwan, mainland China, and South Korea seem to adopt English names and discontinue their use of ethnic names (Chen, 2013; Edwards, 2006; Kim, 2007). Meanwhile, Power (2008) stated that some overseas Japanese choose to use Western names when residing in English-speaking countries, and these Western names sometimes sound similar to their Japanese names. They also may be truncated versions of their Japanese names (e.g., Kaz is a shortened form of Kazuyuki) for ease in pronunciation. When East Asian students study in English-speaking countries, sometimes they feel coerced to use English names recommended by their teachers in ESL classrooms. Particularly, there has been a great tendency for native English teachers to 
recommend Western names to English language learners in Australia (Burke, 2001). According to Burke, the reasons for these recommendations include the difficulty of ethnic name pronunciation and memorability, the occurrence of embarrassment between the student and the teacher, and the facilitation of classroom dynamics. In other words, students believe that their use of English names is strongly linked to their classroom participation, because these names are easier for native English teachers to memorize and, therefore, call on students to answer questions.

Korean names especially with regard to pronunciation and phonotactic constraints are also daunting for Americans. The failure to preserve their ethnic names within a community may motivate Korean American women to give their children English names rather than Korean names. When Korean Americans use ethnic names in the American community, they encounter dilemma in their social networks and have a struggle to be accepted by the community because "issues of both pronunciation and Romanization with their Korean names [...] can be extremely traumatic for children" (Thompson, 2006, p. 203). Furthermore, Kim (2007) echoes Thompson's argument that Korean immigrants who favor Anglicised names show greater assimilation and involvement in Canada, whereas those who maintain ethnic names tend to have less contact with local Canadians. Pronunciation seems to be a dominant reason for Korean immigrants, in particular, to use English names instead of ethnic names. Since many aspects of the traditional culture of Korea, such as naming practices and kin relationships, are similar to Chinese counterparts, it may be worth examining Chinese students' attitudes toward English name adoption. Perhaps not surprisingly, using English names enables Chinese students to develop cultural identity in an English-speaking context. Adopting an English name seems to be an inevitable compromise; English names of Chinese students living in Britain allow them to retain their cultural identity because English names "can enable them to feel that they belong to a cultural group in a society in which they can perceive themselves to be, and in some cases are, treated as Other" (Edwards, 2006, p. 101).

On the other hand, Heffernan (2010) examined East Asian international students' attitudes toward English name adoption in an English-speaking environment. He disputed a hypothesis that pronunciation or linguistic pragmatics is the sole factor that causes East Asian students in Canada to use their English names. Instead, he concluded that Chinese and Korean international students are more likely than Japanese international students to use English names rather than maintain their ethnic names because of different cultural backgrounds with regard to naming practices. He argued that unlike the Japanese students, Chinese and Koreans students use different personal names during different periods of their life, and this increases the likelihood of their English name usage in Canada.

Heffernan's cross-cultural study on East Asian students' use of English names is original, yet a bit problematic. First, he categorized three distinct groups of respondents whose families came from mainland China, Hong Kong, and Taiwan as being of "Chinese ethnicity." This classification may have simplified his definition of Chinese ethnicity; however, it is doubtful that Taiwanese international students identify themselves as "Chinese" with respect to their cultural affiliation. Furthermore, although China and Taiwan share an adjacent geographical border, he neglected to consider that their cultures are similar but not the same. For example, the Taiwanese do not use several personal names during their life span like their Chinese counterparts do. Whether Taiwanese international students possess the same attitudes toward English name adoption as students from Hong Kong and mainland China or even Korea remains to be answered.

The above discussion of Asian international students' and immigrants' English and ethnic names helps readers gain a better understanding of how researchers study English and ethnic names of East Asian students and their resulting identity formation. Without fully understanding the singularity of each culture, it is erroneous to judge that East Asians who adopt English names as disavowing themselves of their own ethnic cultures or having blind faith in Western cultures. Under this framework, the purpose of the present study is twofold. First, I investigate the reasons for Taiwanese international students to adopt and use English names. I pay attention to the processes of their English name adoption and examine the sociocultural factors that motivate them to use English names in Taiwan and in the United States. Second, I explore the extent to which their name choices influence their formation of identity.

\section{Methodology}

\subsection{Data Collection}

This study took place in an American university in 2012. I undertook semi-structured interviews with ten research participants from a regional university in the western United States. Semi-structured interviews enable the researcher to explore the meanings participants attribute to their everyday practices. Interviews were conducted one-on-one in a quiet study room on campus, and each meeting lasted between 70 and 90 minutes. This data collection method turned out to be very informative in that the researcher and researched were able to openly discuss in-depth issues as to when, how, and why an English name was given or chosen, for example. The dynamic discussion allowed the researcher to probe the issues raised by the researched; therefore, complex questions were further clarified.

\subsection{Participants}

Ten Taiwanese international students were recruited based on their country of origin. I define Taiwanese international students as those students who were born and raised in Taiwan and later came to study in the United States. Each participant possessing a Republic of China (ROC) passport, an F1 student visa as well as Form I-20 allowed him or her to legally reside in the United States and enroll in courses.

The average age of the participants was 26.6 years old. Their first languages included Mandarin, Taiwan Southern Min, and Taiwan Hakka. English was the first foreign language that they learned through compulsory education instead of acquiring it at home in Taiwan. All of them considered speaking Mandarin in interviews was the most effective 
language; as a result, they chose to respond to interview questions in Mandarin. With regard to their levels of education, two participants were pursuing bachelor's degrees, while the rest were receiving graduate education.

I recruited the participants based on snowball sampling. I applied this sampling strategy because the share of Taiwanese within the university's large student population (30 448 in 2012) was only between one percent and two percent. Such a small portion of Taiwanese international students had prevented me from reaching potential participants. Consequently, a qualitative research design using snowball sampling was well-suited (Esterberg, 2002). Table 1 below presents the information of each participant's English name and gender. Three male and seven female students participated in this study. It is noted, however, that two female students had identical English names Ivy; their Chinese surnames were added to disambiguate the identifiers.

Table 1. Participants

\begin{tabular}{ll}
\hline English Name & Gender \\
\hline Andy & Male \\
Wayne & Male \\
Eddio & Male \\
Shih & Female \\
Claire & Female \\
Melody & Female \\
Ivy Li & Female \\
Berry & Female \\
Ivy Lin & Female \\
Cynthia & Female \\
\hline
\end{tabular}

\subsection{Data Analysis}

I adopted a general inductive approach for qualitative data analysis (LeCompte \& Schensul, 1999; Thomas, 2006) in this study. All interviews were recorded via a laptop and a Smartpen. In addition to audio recording, I took notes during each interview session. After data collection was completed, I transcribed the recordings and then employed Creswell's coding process in inductive analysis (Creswell, 2008). Another procedure used to access the validity was respondent feedback (King \& Horrocks, 2010), in which I returned my initial analysis to the participants, and I asked them whether my interpretations accurately presented their experience. I invited those who disapproved of my interpretations to participate in an informal follow-up interview in order to reflect on their thoughts. Due to space limitations, I have translated their quotes from Mandarin into English.

\section{Results and Discussion}

During the interviews, ten participants shared their personal stories regarding their original purpose of adopting and using their English names in Taiwan and in the United States as well as when and how their English names were chosen or given. Key findings include the following:

\subsection{English Names Derive from Private English Education in Taiwan}

A small but significant number of Taiwanese people tend to pick a fixed number of English names if the sound of their Chinese names is phonetically similar to specific English names. This may explain why the frequency of certain English names used by the Taiwanese occurs much higher than others. Adaptation or phoneme substitution (Campbell, 1999) is one of the English personal naming strategies. A Taiwanese whose Chinese name contains the phoneme [t6] has a higher tendency to adopt an English name with the nearest phonetic equivalent [dz] in that the phonetic property of these two sounds mainly contrasts in voicing. An acclaimed Taiwanese singer, Jay Chou, Chou Chieh-Lun 周杰倫, is an example. The sound of the first character in his Chinese given name 杰 [tcie] is nearly homophonous with Jay [dzeI] and thus motivated him to adopt this name.

In this study, Wayne also exemplifies a similar pattern. While recalling the origin of his English name, Wayne reflected that a pre-school English teacher gave him this name because the second character of his Chinese given name, Wei 緯, and Wayne sound very much alike. Taiwanese students' adoption of English names originating from the phonetic similarity may enable them to maintain social identity and avoid identity confusion. Wayne never changed his English name growing up and has extended his continued use of this name to his life in the United States. As Wayne described, "Names represent yourself, yourself in a whole; even if my name is pronounced in a different language, I still hope to preserve myself in a part." The sound similarity between his Chinese and English name helped others to associate both names with his identity. By using a phonetically related English name, the identity between the one who is signified and the two signifiers, that is two names, is inherently integrated. This parallels the following assertion that "[students] take on different ones closely related to their Chinese names. This might be an attempt to guard against identity split, or incorporate the English speaking identity into the native culture identity" (Gao, Xiu, \& Kuang, 2010, p. 10).

Other participants like Wayne who acquired his English name at a young age in Taiwan reveal a discernible pattern. Nine of ten participants reported that they first used their English names in Taiwan, whereas one began using her English name after studying abroad. In addition, seven of them acquired their first English names either in preschool or in elementary school. Adopting English names at an early age seems to be a ubiquitous and popular cultural 
phenomenon among Taiwanese students which led Cynthia to remark, "Almost every Taiwanese person adopts an English name. . . . Like me, I had an English name when I was little. That's why we get used to having another name."

The majority of the participants were given English names by others: half of the participants' first English names were given by their private language school teachers, two by relatives, and one by a high school English teacher. Most importantly, all participants hold the view that it is normal for both native and non-native English speaking teachers in Taiwan to give students English names. The findings show that eight of the ten Taiwanese international students, while living in Taiwan, had been sent by their parents to private English institutions, such as language schools or cram schools. Given that English teachers insisted on calling students by their Chinese names in English classrooms, the participants said they felt something was wrong. Both Ivy Lin and Ivy Li were private English language school teachers in Taiwan. When they talked about their past career experiences, they deemed it not only prudent but also imperative to assign English names to their students based on the pressure from social environments and social expectations. They said,

Ivy Lin: Since [students] come here to learn English, you have to begin with your (English) names, because you have to let people know who you are. When people are calling you or talking to you, they do these by calling your name, and you'll know they are talking to you. So, since you come here to learn English, you need to have an environment, so I think names are, you know, introduction, first step.

Ivy Li: Taiwanese teachers, uh because we don't want to confuse students, so in this way, whenever he is in this classroom, classmates, Taiwanese teachers, foreign teachers, and the director all call him by his (English) name, and even when we communicate with their parents, we call out . . . In fact, their parents somehow believe that they're participating in their children's growth. They hope that their children can be fully immersed in English. Their children will become intrinsically different, including their English names.

The findings of this study suggest that Taiwanese students do not adopt their English names by choice. Furthermore, private English education in Taiwan is substantially intertwined with the students' acquisition of their English names. Parental involvement outside of class is conducive to children's better academic performance among East Asian countries (Ho, 2009). Taiwanese parents have exceedingly high expectations toward their children, and some believe that their children's achievements can be quantified and have direct relevance to their academic scores. Many Taiwanese parents consider that learning English provides a head start in building children's intellectual foundations. The growing private education industry in Taiwan demonstrates that parents are not reluctant to invest in their children's English education at an early age. The abundance of private chain language schools in Taiwan, including Hess, Giraffe, and Sesame Street, are deemed as an alterative way to improve children's English communication skills beyond compulsory English education at school. Advanced English skills enhance the likelihood of acceptance to topnotch schools and eventually better-paying jobs in the long-run.

When Taiwanese parents send their children to these private English institutions, it is a norm for English teachers to assign an English name to every student. According to the statements made by the participants in this study, they do not challenge their teachers' power to give them English names, nor do they question the need to use English names in English classrooms. Their compliance to teachers may be rooted in Taiwanese social conventions. In Taiwan, both home education and school education instill in children deference to teachers. Moral values of Confucianism have always been taught to teens so that they will practice behaviors that reinforce social harmony and social order. Their resistance and challenges to authorities, such as parents and teachers, are regarded as deviations from the social norm. On the one hand, English teachers often treat English names as an accelerator to help students accommodate themselves to English learning environments. On the other hand, students' absolute acceptance of English names illustrates that students must abide by teachers who are empowered to assign English names to them. As a result, an English name is an authoritative order instead of personal choice.

\subsection{The Choice of Names is Constrained by Social and Linguistic Factors}

After the participants left their hometowns in Taiwan and settled in the United States, all were most often addressed by their peers on- and off-campus with their adopted English names rather than by their ethnic names. This practice is accepted and considered normal by students as well as other Taiwanese sojourners. As Shih recalled, she preferred to use English names to address her Taiwanese peers, "Like you all (who come from Taiwan), I often call you by your English names . . . and actually we're still speaking Chinese (laugh). It's so funny." While the participants contemplated whether their names influence their experience of cultural adaptation in the United States, many of them adopted their English names as a bridge for acculturation. The following is Eddio's reflection of attending an off-campus Taiwanese social gathering where he encountered another Taiwanese student:

Eddio: In Taiwanese people's mind, you'd have an English name. Everyone subconsciously has a consensus that you probably have an English name. For example, a person didn't have an English name in our group, and when he said, "I'm 大鈞." You'd say, "You don't have an English name, right?"

The findings show that all participants in this study, when asked which names they used to introduce themselves to Taiwanese peers in the United States, chose their English names. Like all participants, Eddio and Shih did not specify whether they use their ethnic or English names to distance or associate themselves from the Taiwanese community. 
Nevertheless, there exist underlying principles within the community regarding what practices should or should not be applied, and these principles have never been straightforwardly outlined. The Taiwanese international students perceive their use of English names among Taiwanese peers as a prerequisite for upholding group solidarity, whereas the use of ethnic names appears to be discouraged. They described their few Taiwanese peers who use ethnic names as unique and even idiosyncratic. The students who use ethnic names within their social networks are not subject to social marginalization, but such use of ethnic names leads to objections, such as questioning and even ridicule. Therefore, members of a group develop a group identity through behaving more similarly within their community. In other words, Taiwanese international students have made inroads into the Taiwanese network of a specific college through the practice of using English names. Taiwanese international students create conditions enabling them to become insiders and in-groups (Tajfel, 1978) and to gain acceptance in the host culture through the use of English names.

With regard to linguistic constraints, pronunciation seems to be one of the essential reasons causing the participants to use English names in social settings in the United States. They reported that not only non-Chinese speaking students (e.g., American and international peers) often fail to pronounce their ethnic names in a proper way, but also the participants believe that their English names are relatively easier than ethnic names to remember. They are more likely to use their English names in the United States to preclude the possibility of mispronunciation of their ethnic names by non-Chinese speaking students.

The side-effects of mispronunciation of some Taiwanese students' ethnic names may be more hurtful than non-Chinese speaking students can imagine. Sometimes non-Chinese speaking students are unaware that their off-toned pronunciation, though unintentionally, can be severely humiliating to the Taiwanese students. Mandarin is a tonal language. The four different tones in Mandarin contrast in lexical meanings. That is, if a Taiwanese's ethnic name is pronounced with improper tones, the symbolic meanings embedded in one's name may change drastically and even trigger embarrassment. For instance, Melody reported that her Taiwanese female friend whose Chinese given name, Wéi-Jú 偉如, is often carelessly pronounced as Wèi-zhu 餵㨋 (feeding pigs) by non-Chinese speaking peers. The awkwardness impelled her to conceal her ethnic name from others and urged American peers to call her by her English name. Moreover, repetitive unsuccessful pronunciation by non-native Chinese speaking students also causes the participants' negative feelings and can be a threat to some participants. Shih, Claire, and Wayne had repeatedly tried to teach American peers to pronounce their ethnic names appropriately, but every attempt ended in a blunder. As they illustrated,

Shih: When I was studying at a community college, sometimes the teacher felt that Hui was hard to pronounce, perhaps her tone was off . . . yes, anyway, I thought it's easier for those people who are nonnative speakers of Chinese to pronounce Shih, and therefore I went by it.

Claire: I feel like it's a bit odd when I hear Wan-Ting Wang directly translated from my Chinese name. In addition, some foreigners cannot pronounce your name. I would rather adopt a name that they can recognize and it's easier for them to remember than a name that can't be pronounced.

Wayne: When you're teaching foreigners to pronounce your name, I mean it's not a problem when their pronunciation is ok, but when their pronunciation is not ok, and you're like gosh! What are they calling? And they're actually calling you, and you're like, my name doesn't sound like that. Why are you insisting on that? I feel uncomfortable.

When interacting with American and international peers in the United States, Taiwanese international students choose to use their English names, because non-Chinese speaking students often have a difficult time pronouncing their ethnic names. An alternative English name is offered to relieve pressure and embarrassment between the speaker and addressee. The results suggest that ethnic names foment feelings of estrangement, whereas English names break the language barrier and social misunderstanding. Consequently, American peers may have more contact with Taiwanese international students if Americans can pronounce and remember their English names. Taiwanese international students thereby gain acceptance by Americans through using English names, which suggests that they may have a higher chance of assimilating into the mainstream culture.

\subsection{English Names Disclose National and Cultural Identity}

The social and linguistic factors licensing the participants' use of English names is likely to preoccupy them. Many Taiwanese people are not seriously concerned with the maintenance of their ethnic names in the United States. The use of English names in the United States by the Taiwanese may be influenced by national identity and cultural identity. Eddio and Ivy Lin commented,

Eddio: Taiwan is a multicultural country. Since we get accustomed to receiving information from other countries, we seem to forget our roots. I wouldn't say forget; I would rather say we don't relatively respect our roots. I feel like I'm the same; I don't care for anything. At the same time, I can accept everything. On the one hand, we can accept many new things. On the other hand, I don't respect things our ancestors passed down. ... As for Taiwanese, they might wonder if that's really serious. Names are merely names. 
Ivy Lin: I think the Taiwanese, especially the younger generation, are willing to accept foreign cultures, and they don't ponder over the issue of sacrificing self-esteem, you know, as if they devalue [themselves] and cater to other cultures. I don't think they may care what they are.

Like Eddio and Ivy Lin, the participants of this study lamented that Taiwanese people's pride in their country is rapidly diminishing. For them, the younger generation's adoption and use of English names entails a loss of national identity. Taiwan's national identity and its knotty relationship with mainland China have been widely addressed in historical, political, and sociological domains. Kumaravadivelu (2008) argues that the facilitation of cultural globalization has driven an increasing number of nations to become "emboldened to seek autonomous status" (p. 151), and this concept also propels the Taiwanese to ask for equality in international affairs. With regard to the current national status of Taiwan, not only has the country been excluded from the United Nations since 1971 (Christensen, 2002) but also the failure to use "Taiwan" rather than "Chinese Taipei" at international sporting events (e.g., the Olympic Games) frustrates and infuriates the Taiwanese. The seemingly everlasting disputes over Taiwan's nationalism moreover have continuously been raised by Taiwan's two primary political parties - the Kuomintang (KMT) and Democratic Progressive Party (DPP). It is because of this historical background that some Taiwanese are apprehensive about their country's international status; this anxiety may complicate the construction of national identity.

Four participants explicitly expressed that American values, either physically or virtually, play a pivotal role in influencing the Taiwanese culture. Not only do most modern technologies and innovations effortlessly arrive in Taiwan from the United States, but the influx of English names penetrates Taiwanese people's daily lives as well. Many participants believe Taiwanese people are not strong-willed and that they adjust their attitudes and manners to please others. That is to say, Taiwanese people adopt English names in the United States in order to better assimilate into American student life. This aspect of their personalities may highly influence their adoption of English names in the United States.

The findings suggest that the Taiwanese's pride in their nation and culture may be correlated with their discontinued use of ethnic names in the United States. For the participants, Taiwan's ambiguous international status and Taiwanese people's accommodating character may be one of the conclusive factors shaping their identities and therefore their use of English names. Interestingly, the participants claim that Taiwanese people in general are united even thought they do not use ethnic names in the United States. The majority of them revealed that the embrace of English names is not synonymous with renunciation of one's belief in his or her country or culture.

The use of English names by Taiwanese international students may represent both the processes of assimilation and acculturation. Although they use their English names with American peers, they do not discard their roots, traditions, or heritage. Eight participants of this study identified their ethnicity as Taiwanese and categorically reject that Chinese and Taiwanese are the same, whereas two identified themselves as both Chinese and Taiwanese. Taiwanese international students preserve their Taiwanese identities and cultures by means of daily practices. On the one hand, they acculturate themselves by speaking English, using English names, and celebrating conventional American holidays and festivals, such as Christmas and Thanksgiving. On the other hand, they speak their mother tongue with their Taiwanese peers, celebrate Taiwanese traditional festivals (e.g., Chinese New Year and Mid-Autumn Festival), and remain engaged with the current political and socio-economic situation in Taiwan. Taiwanese international students endeavor to sustain their culture while appreciating the host culture. Cultural identity is often fluid, and it can only be developed through the interaction with insiders and outsiders as well as the host culture and home culture. As Hall claims, "cultural identity [...] is a matter of 'becoming' as well as of 'being'. It belongs to the future as much as to the past. It is not something which already exists, transcending place, time, history and culture" (Hall, 2003, p. 236).

\section{Conclusion}

Social rules govern the way we interact with others. We learn the rules from institutions, for instance family and educational institutions, and behave in accordance with what our society expects. Taiwanese international students acquire their English names from private English schools in Taiwan, and their use of English names is governed by the asymmetric power between teacher-student relationships. They extend the use of English names from Taiwan to the United States. Even though their choice of ethnic and English names among peers is often constrained by social and linguistic factors, English names greatly influence their acculturation and the development of identities.

Previous studies on English name adoption by East Asian students and immigrants center primarily around the cultural gap caused by pronunciation problems between native speakers and non-native speakers. The present study has furthered our understanding that social morality and social interaction may equally motivate Taiwanese students to extend their English names used in Taiwan to the United States. In summary, it is because Confucianism underscores social order so that Taiwanese students find themselves unable to refuse English names given to them by their teachers in Taiwan's EFL context. Moreover, to maintain a positive face in a new sociocultural setting, Taiwanese international students acquire implicit norms that using an English name is favored and agreed upon by their speech community. This practice is exemplified by the research participants whose English names helped them find ways to socialize with their peers, influencing those who shared the same cultural identity to continue using their English names in the United States.

The findings of this study could be biased based on how I recruited the participants and the sampling strategy that I employed. As stated in the section on participants, this case study is based on this small sample; therefore, the findings 
are not likely to be representative and may contain subjective biases. Furthermore, the participants were recruited via snowball sampling. This strategy carries certain risks; nevertheless, semi-structured interviewing enabled me to explore how the use of a Chinese or English name shapes individual identities. The mutual understanding between the interviewer and interviewee helped minimize the gap that has recurrently appeared between the researcher and researched. I believe that the participants were more open to disclosing personal stories and voicing their opinions because of our shared ethnicity and country of origin. It is highly recommended that further research be conducted on English names of Taiwanese returnees to examine whether they would continue or discontinue using English names in their social contexts, such as workplace, after they complete their studies in the United States and return to Taiwan.

\section{Acknowledgements}

The major findings of this study are extracted from the author's Master's thesis.

\section{References}

Burke, R. (2001). Western names in the classroom: An issue for the ESL profession. TESOL in Context, 11(1), 21-23.

Campbell, L. (1999). Historical linguistics: An introduction. Cambridge, MA: MIT Press.

Chen, Y. (2013). A study on Taiwanese international students and Taiwanese American students: The interface between naming and identity (Master's Thesis). Available from ProQuest Dissertations and Theses database. (UMI No. 1533008)

Christensen, T. J. (2002). The contemporary security dilemma: Deterring a Taiwan conflict. The Washington Quarterly, 25(4), 5-21. http://dx.doi.org/10.1162/016366002760252509

Creswell, J. W. (2008). Educational research: Planning, conducting, and evaluating quantitative and qualitative research. Upper Saddle River, N.J: Pearson/Merrill Prentice Hall.

Edwards, R. (2006). What's in a name? Chinese learners and the practice of adopting 'English' names. Language, Culture, and Curriculum, 19(1), 90-103. http://dx.doi.org/10.1080/07908310608668756

Esterberg, K. G. (2002). Qualitative methods in social research. Boston: McGraw-Hill.

Gao, Y., Xiu, L., \& Kuang, W. (2010). "I want to be a captain of my own heart"-English names and identity construction by English majors in a comprehensive university. Chinese Journal of Applied Linguistics, 33(2), 3-17.

Hall, S. (2003). Cultural identity and diaspora. In J. E. Braziel, \& A. Mannur (Eds.), Theorizing diaspora: A reader (pp. 233-246). Malden, MA: Blackwell.

Heffernan, K. (2010). English name use by East Asians in Canada: Linguistic pragmatics or cultural identity? Names: $A$ Journal of Onomastics, 58(1), 24-36.

Ho, E. S. (2009). Educational leadership for parental involvement in an Asian context: Insights from Bourdieu's theory of practice. The School Community Journal, 19(2), 101-122.

Institute of International Education. (2011a). Opendoors 2011 "fast facts". Retrieved from http://www.iie.org/ /media/Files/Corporate/Open-Doors/Fast-Facts/Fast\%20Facts\%202011.pdf.

Institute of International Education. (2011b). International student enrollment increased by 5 percent in 2010/11. Retrieved from http://www.iie.org/Who-We-Are/News-and-Events/Press-Center/Press-Releases/2011/2011-11-14Open-Doors-International-Students.

Kim, T. (2007). The dynamics of ethnic name maintenance and change: Cases of Korean ESL immigrants in Toronto. Journal of Multilingual and Multicultural Development, 28(2), 117-133. http://dx.doi.org/10.2167/jmmd419.1

King, N., \& Horrocks, C. (2010). Interviews in qualitative research. Thousand Oaks, CA: Sage.

Kumaravadivelu, B. (2008). Cultural globalization and language education. New Haven: Yale University Press.

LeCompte, M. D., \& Schensul, J. J. (1999). Analyzing and interpreting ethnographic data. Walnut Creek, CA: AltaMira.

Li, D. C. S. (1997). Borrowed identity: Signaling involvement with a Western name. Journal of Pragmatics, 28(4), 489513. http://dx.doi.org/10.1016/S0378-2166(97)00032-5

Power, J. (2008). Japanese names. The Indexer, 26(2), C4: 2-6.

Tajfel, H. (1978). Differentiation between social groups: Studies in the social psychology of intergroup relations. London: Academic Press.

Thomas, D. R. (2006). A general inductive approach for analyzing qualitative evaluation data. American Journal of Evaluation, 27(2), 237-246. http://dx.doi.org/10.1177/1098214005283748

Thompson, R. (2006). Bilingual, bicultural, and binominal identities: Personal name investment and the imagination in the lives of Korean Americans. Journal of Language, Identity, and Education, 5(3), 179-208. http://dx.doi.org/10.1207/s15327701jlie0503_1 